NASA Technical Memorandum 107263

\title{
Load-Following Power Timeline Analyses for the International Space Station
}

James Fincannon, Ann Delleur, Robert Green, and Jeffrey Hojnicki Lewis Research Center

Cleveland, Ohio

Prepared for the

31st Intersociety Energy Conversion Engineering Conference cosponsored by IEEE, AIChE, ANS, SAE, AIAA, and ASME Washington, D.C., August 11-16, 1996

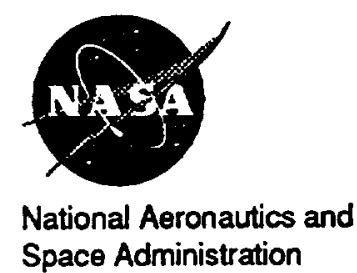




\section{'}




\title{
LOAD-FOLLOWING POWER TIMELINE ANALYSES FOR THE INTERNATIONAL SPACE STATION
}

\author{
James Fincannon, Ann Delleur, Robert Green, Jeffrey Hojnicki \\ NASA Lewis Research Center \\ 21000 Brookpark Road, MS 500-203 \\ Cleveland, Ohio 44135 \\ Phone: (216) 433-5405 \\ Fax: (216) 433-2995 \\ Email: fincannon@lerc.nasa.gov \\ WWW: http://godzilla.lerc.nasa.gov/pspo.html
}

\begin{abstract}
Spacecraft are typically complex assemblies of interconnected systems and components that have highly time-varying thermal, communications, and power requirements. It is essential that systems designers be able to assess the capability of the spacecraft to meet these requirements which should represent a realistic projection of demand for these resources once the vehicle is onorbit. To accomplish the assessment from the power standpoint, a computer code called ECAPS has been developed at NASA Lewis Research Center that performs a load-driven analysis of a spacecraft power system given time-varying distributed loading and other mission data. This program is uniquely capable of synthesizing all of the changing spacecraft conditions into a single, seamless analysis for a complete mission. This paper presents example power load timelines with which numerous data are integrated to provide a realistic assessment of the load-following capabilities of the power system. Results of analyses show how well the power system can meet the time-varying power resource demand.
\end{abstract}

\section{INTRODUCTION}

The International Space Station (ISS) is a complex assembly of interconnected systems and elements that have highly timevarying thermal, communications, and power requirements. Resource providers (e.g. power, thermal, communication systems) must assess, prior to launch, whether their systems can meet the demands of the resources consumers. Therefore, system designers assemble the various resource requirements into operational timelines representative of typical mission profiles. The timelines include the effects on component operation from the mission goals and requirements, astronaut activity schedule, operational constraints, and control strategies. Typically, mission timelines are required for each ISS assembly stage and can cover time periods from a few days to a month or more. Once these timelines are formulated, all resource providers must verify the ability of their systems to meet the requirements specified by the timelines and address issues that arise through the inter-system synthesis. This process is known as a Design Analysis Cycle (DAC).

During a typical timeline, many events occur which impact the ability of the electric power system (EPS) to meet the required load demand. In addition to the changing magnitude and location of the electrical load demand, the station attitude, station configuration, EPS architecture, and solar array pointing conditions may change many times during a mission. A computer program called ECAPS has been developed by NASA Lewis Research Center's Power System Project Office that integrates and assesses the changing conditions of the entire mission from the power perspective. ECAPS simulates the control methodologies that will be used on orbit, realistically operating the EPS to supply a distributed time-varying load demand. Batteries are charged and discharged based on power demand and solar array power production. Solar array pointing is based on tracking algorithms. Many other factors are considered in the analyses including the articulations of the solar arrays and radiators throughout the mission to accommodate Shuttle proximity operations: the ISS vehicle orientation to accommodate Shuttle operations: ISS assembly and thermal requirements: and the effects of shadowing on the solar arrays by other station structures.

\section{BACKGROUND}

ECAPS continues the logical development of another computer program called SPACE (Station Power Analysis for Capability Evaluation). SPACE was originally developed at NASA Lewis Research Center in 1988 (Hojnicki, 1991) (Hojnicki. et al.. 1992. 1993) (Kerslake, et al., 1993). Its original purpose was to 
perform independent verification and validation of the space station EPS contractor's performance predictions. This program merged orbit mechanics algorithms with detailed EPS performance models to predict EPS continuous power capability under a wide variety of conditions. SPACE's unique capabilities for performing a variety of analyses had led to its extensive use during space station redesigns to support the NASA Space Station Program Office in power system performance assessments.

SPACE is a quasi-steady-state model where, electrically, all of the components are treated as if they are at steady-state. However, SPACE performs a time-variant analysis through an orbit to account for factors that change slowly, such as array temperature and battery voltage. SPACE uses a "source-driven", or forward, calculation to determine the capability of the EPS. ECAPS (which is simply the reverse acronym of SPACE) performs a backward, or "load-driven", calculation that assesses the ability of the EPS to supply a given electrical load demand. ECAPS shares the majority of its code with SPACE. However, SPACE requires the EPS to be operated in an energy balance condition, where the batteries are fully-recharged every orbit ECAPS makes no such assumption.

ECAPS is used for any type of analysis where the user load profile is known, and the ability to meet the load must be assessed. Detailed time-phased load profiles throughout two week missions are supplied as input by the Space Station Systems Engineering Office, NASA Johnson Space Center, and these are coupled with detailed array pointing timelines and on-orbit configurations. The outputs of these ECAPS analyses include battery depth-of-discharge (DOD) throughout the mission and the identification of any EPS hardware limit violations.

Often, power system analyses are performed for a specific orbit, with a specific system configuration and a specific station attitude. That type of analysis is valuable, but for a highly complex system like ISS, many different factors often change significantly during a mission. This can induce subtle effects which could not normally be detected during such a static assessment. ECAPS, however, has the unique ability to combine the time-varying load demand, station configuration, attitude, and pointing conditions into a single integrated analysis that provides an immediate assessment of the combined effects of all of these changes.

\section{ALGORITHMS}

Figure 1 shows a simplified outline of ECAPS. It includes subsystems to analyze orbit mechanics, solar array pointing, solar array shadowing, solar array performance, battery performance, and power management and distribution equipment performance.

The orbit mechanics subsystem models a circular orbit. The subsystem determines the sun vector, solar flux, solar beta angle, eclipse time, and orbit period, essential to many of the other calculations in the program. The pointing subsystem determines the solar array pointing condition based on the orbit mechanics output and the station attitude. It includes consideration of rotation gimbal rates and gimbal position limits (or keep-out zones). The user can specify allowable gimbal limits or pointing strategies for each array. For instance, if by fully tracking the sun, one solar array shadows an adjacent array, the user can select to have both solar arrays off-point to avoid shadowing, thus improving the overall power production.

The shadowing analysis subprogram uses the sun vector, spacecraft attiude, gimbal angles, spacecraft geometry, and array wiring layout to determine the spatially distributed deactivation of cell-submodules on each solar array (Fincannon, 1993, 1995). A cell-submodule is a collection of adjacent interconnected solar cells. On the ISS solar array, cell-submodules are connected width-wise on the solar array (called strings) such that a number of strings exist along the length of the solar array. Current loss due to array shadowing is not proportional to the shadowed array area because of the cell-submodules connectivity, making it essential to know the spatial distribution of shadowing.

The solar amay performance subsystem uses the industry standard Hughes single diode model to determine solar cell performance based on empirical data for various cell grades. These data are corrected for temperature, illumination level (including shadowing), blanket flatness/alignment errors, array pointing errors and environmental degradation. Array operating voltage, power and temperature are iteratively determined.

The battery subsystem uses empirical models that scale from actual voitage data taken at several operating conditions. The model determines a battery voltage for the current rate or power load being applied to the battery at each point in the simulation. The voltage determined is a function of DOD and battery age. Once the voltage is determined, the model calculates thermal load and DOD for the present time step. The model also accounts for the variation in coulombic efficiency during charge.

Power management and distribution performance subprograms model components in various degrees of complexity. Component models consist of combinations of parasitic loads, efficiency curves, and resistive losses. Power, current, and voltage limits are monitored for many components. If any of these limits are exceeded, the load demand on that channel is shed, such that the analysis may continue. ECAPS uses a load flow model to distribute currents and voltages throughout the distribution system.

\section{DATA MODELS}

In order to perform the load-driven analysis, data from numerous sources must be synthesized and time-phased. These data include electrical load demand, station geometry. EPS configuration. station attitude, and solar array pointing.

The electrical load demand is obtained from the Station Engineering Office at Johnson Space Center (Morris and Sheppard, 1992) (Morris, 1996). The load demand is determined by assessing the necessary mission activities, the equipment needed to accomplish these activities, the location and 
connectivity of the equipment, and the operational characteristics of the equipment (e.g. duty cycle, nominal power level, maximum power level, etc). This results in a spatially distributed load demand at each dc-dc converter unit (DDCU). Load profiles typically have variable time steps, sometimes as small as one second. In order to integrate these timelines into ECAPS, the time steps must be adjusted to an optimum, larger interval that reduces calculation time while maintaining accuracy. Studies have shown that one minute time steps are adequate for most uses, although smaller intervals can be used. Figure 2 shows an example load profile for two EPS channels. This is the summation of the power demands on all DDCUs connected to those channels. On ISS, there are as many as 34 DDCUs total, with up to 7 on a channel.

Changes to the EPS configuration must also be considered. During ISS assembly, additions to and reconfigurations of the EPS are necessary, including the addition of entire power channels, addition of batteries, addition of electronic components, and changes in connectivity. These changes along with their timephasing are specified in input data files so that power analyses will accurately reflect the changing configuration during the mission. Figure 3 shows the connectivity changes for an example assembly stage. In this stage, DDCUs are activated.

The station geometry is obtained from the Space Station Program Office, which maintains highly detailed solid models of the ISS through its entire assembly sequence. Because of their high level of detail ( $>200000$ polygons), use of these models directly in ECAPS would be unwieldy and not significantly increase the accuracy of the analysis. Thus, less detailed models ( $<2000$ polygons) are developed from the highly detailed ones. In order to properly assess an entire mission, any changes to the station configuration must be accommodated in the geometry model. This includes placement or replacement of station objects and the presence or absence of the Space Shuttle. The geometry file contains descriptors that identify the articulating elements, the pivot points and rotation axes for each articulating element, and the surfaces onto which shadowing will be determined. Figure 3 shows an overview of all the changing factors during a typical analysis, including the changes in station geometry.

For the station attitude and pointing information, the Space Station Program Office defines the operational scenario within a Design Analysis Cycle databook. This information includes the solar beta angle variation and the times when the solar arrays must be locked. Locking, or feathering, of arrays normally occurs during docking and separation activities in order to alleviate structural loads and contamination on the arrays. During normal operation, all arrays are sun-tracking, although occasionally, one axis of rotation must be restricted due to clearance problems with other hardware. The number of solar arrays whose tracking can be affected changes throughout the assemble sequence, but when ISS assembly is complete there are eight U.S. and ten Russian solar array wings which track the sun independently. Figure 3 indicates the changes through the example assembly stage.
During a typical mission, the station attitude changes several times from the nominal coast attitude, to local vertical/local horizontal hold attitude for docking, to a mated attitude, and to a reboost attitude. Detailed time-variant attitude data (yaw, pitch, and roll) are received for periods where the station attitude is changing constantly. These periods include free-drift excursions for Space Shuttle docking and separation, Russian vehicle docking and separation, and planned station attitude maneuvers. Where detailed time-variant attitudes are not available, the attitude envelopes and rate limits are obtained. These are converted to time-variant data for input into ECAPS.

In ECAPS, all these data can be integrated through simple input data files. ECAPS time-phases all the data and integrates the data into a single analysis. Subtle effects can be identified, especially those resulting from combined factors, such as applied loads. array pointing requirements, station geometry modifications, EPS reconfigurations, and station attitude changes. Several examples of combined effects are presented in the next section.

\section{RESULTS}

After assembling all of the data described in the previous section into the ECAPS format, an assessment can be made whether the power system can meet the assembly stage requirements. Figures 4 through 8 show sample output and results for an example two week scenario. Figure 4 shows the solar array power through the mission for two power channels. Figure 5 shows the battery DOD for the same two channels. Each channel has a dedicated set of batteries and solar arrays to provide power. The load demand placed on that channel and the power capability of the solar arrays will determine how deeply the batteries must be discharged. It is desirable to limit the battery discharge to $34 \%$, to optimize battery life. Battery life must be maximized to prevent the necessity of prematurely launching replacement sets. During insolation periods, the batteries are charged whenever possible, but if shadowing or off-pointing is too great, the batteries are discharged to meet the applied load. Space Shuttle docking and separation can be observed in both solar array power and the battery DOD plots. Since the arrays are feathered during docking and separation, array power decreases and thus the battery discharge is increased to meet the loads.

Figure 6 illustrates the ISS orientation, as viewed from the sun. and the shadow patterns on the Russian Functional Cargo Block (FGB), Russian Service Module (SM), and U.S. solar arrays (US PV) for orbit dawn, noon, and dusk. Shadow patterns are projected onto uniform rectangular grids for the purposes of illustration, even though each solar array has different dimensions. The case depicted in this figure was generated at a shadowing intensive solar beta angle $\left(-45^{\circ}\right)$ to show how various parts of ISS and the Space Shuttle can shadow the solar arrays, affecting power capability. For this case, the solar arrays track the sun about only one axis of rotation.

ECAPS allows the user to zoom-in to any portion of the analysis to examine the details. This is a useful feature for examining 
critical events in a two week scenario. Figures 7 and 8 show a zoomed-in portion of the analysis, at Shuttle separation. During this part of the scenario, the station attitude is changing constantly. The dark bars on each figure show the eclipse phase of each orbit. Figure 7 depicts the time-varying yaw, pitch and roll during Space Shuttle separation, which was obtained as input for the analysis. Figure 8 shows the load demand for a representative channel, the solar array power for that channel and the battery DOD. In addition to showing the drop in array power and the corresponding increase in battery DOD to meet the loads during separation, figure 8 shows the rate of battery DOD and recharge during each orbit.

In the case discussed above, even though the DOD reached a relatively high level, the mission was still viable. No hardware limits were exceeded, and the batteries did not become fully discharged. However, this might not be the case for all assessments. The model might detect hardware limit violations, or predict that the batteries will become completely discharge. If battery depth of discharge reaches $100 \%$, the battery is completely drained. This results in a "blackout" on that channel, which is not an acceptable scenario.

Figures 9 and 10 depict the DOD and load exceedence curves for a hypothetical overload condition. For this example, the station orbit was assumed to be at a high solar beta angle, with a abnormally heavy load demand. At this high solar beta angle, the solar array power generation is reduced, and thus, there is insufficient power available to fully recharge the batteries each orbit. The peak DOD on one channel continued to increase during each orbit until the DOD reached $100 \%$. Since a fully discharge battery cannot supply power to meet the load demand, ECAPS "sheds" the part of the load demand which the EPS cannot meet. The amount of this "load shed" is tracked, and can be seen in Figure 10. This is an indication of the level of overload on that channel. The DOD in this case was able to begin recovery prior to docking because, as the solar beta angle decreased with time, the arrays were able to generate more power. When the arrays were feathered for docking, and thus not optimally pointed for power generation, the DOD again increased to $100 \%$ resulting in more load shedding.

Note that in this hypothetical scenario, the overload condition only occurs on one channel. The total EPS capability on all channels might be greater than the total load demand. Thus, a typical "lumped" power analysis, that only considers the total capability, would fail to detect the overload, since the overload was localized on only one channel. In addition to detecting overloads due to batteries becoming fully discharge. ECAPS can also detect conditions where hardware limits are exceeded. As in the case above, whenever hardware limits are exceeded, ECAPS "sheds" the load demand which cannot be met, and tracks the "load shed" throughout the mission.

There are several approaches to alleviating exceedences caused by a combination of shadowing, off-pointing and high load demand. First, the channel loading can be examined and redistributed to another channel that has more capability, or some of the loading can be re-phased to another time during the mission when there is sufficient available capability. Second, the flight attitude can be adjusted to maximize the solar array power (i.e. allow better sun-tracking or reduce shadowing). Although an assessment of ECAPS results can produce recommendations for alleviating the exceedences, individuals responsible for the other station systems must evaluate the impacts of these recommendations on their respective systems. This means that an iterative process is required to resolve problems in assembly stage assessment where power resources are considered synergistically with thermal, communications, data transfer, and other resources.

\section{CONCLUSIONS}

A powerful tool for assessing spacecraft power systems called ECAPS has been developed and utilized at NASA Lewis Research Center. This unique suite of synthesized algorithms makes it possible for an analyst to determine the ability of a spacecraft electrical power system to meet distributed time-varying power requirements. This tool has been used throughout the development of the Space Station program with great success. Future plans for development of this tool include generalization for easy use with any type of spacecraft and an Internet interface using the World Wide Web and virtual reality modeling language.

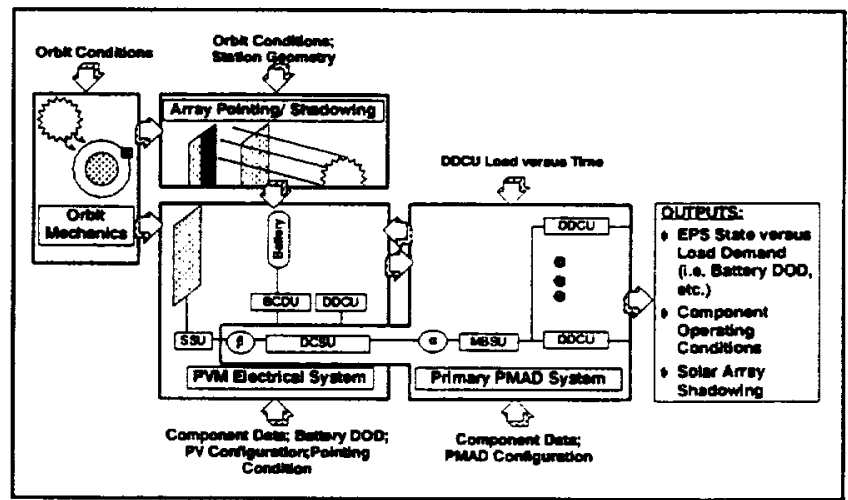

Figure 1: ECAPS Computer Program

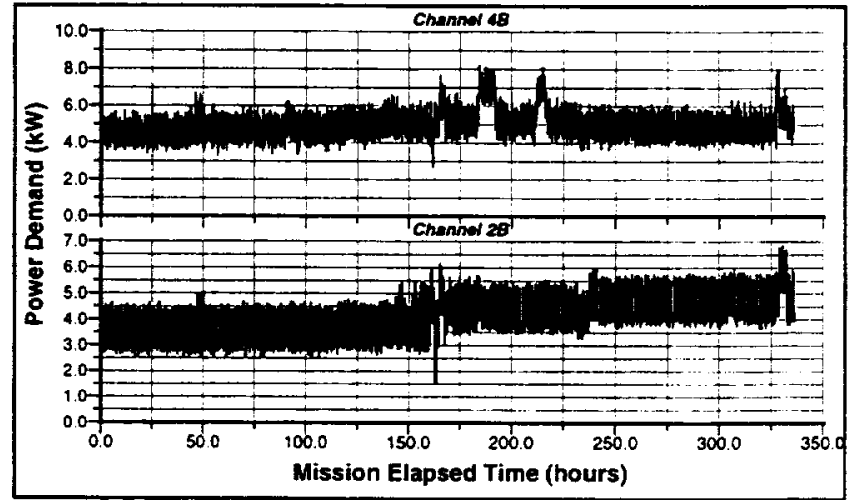

Figure 2: Example Load Timelines for 2 Channels 


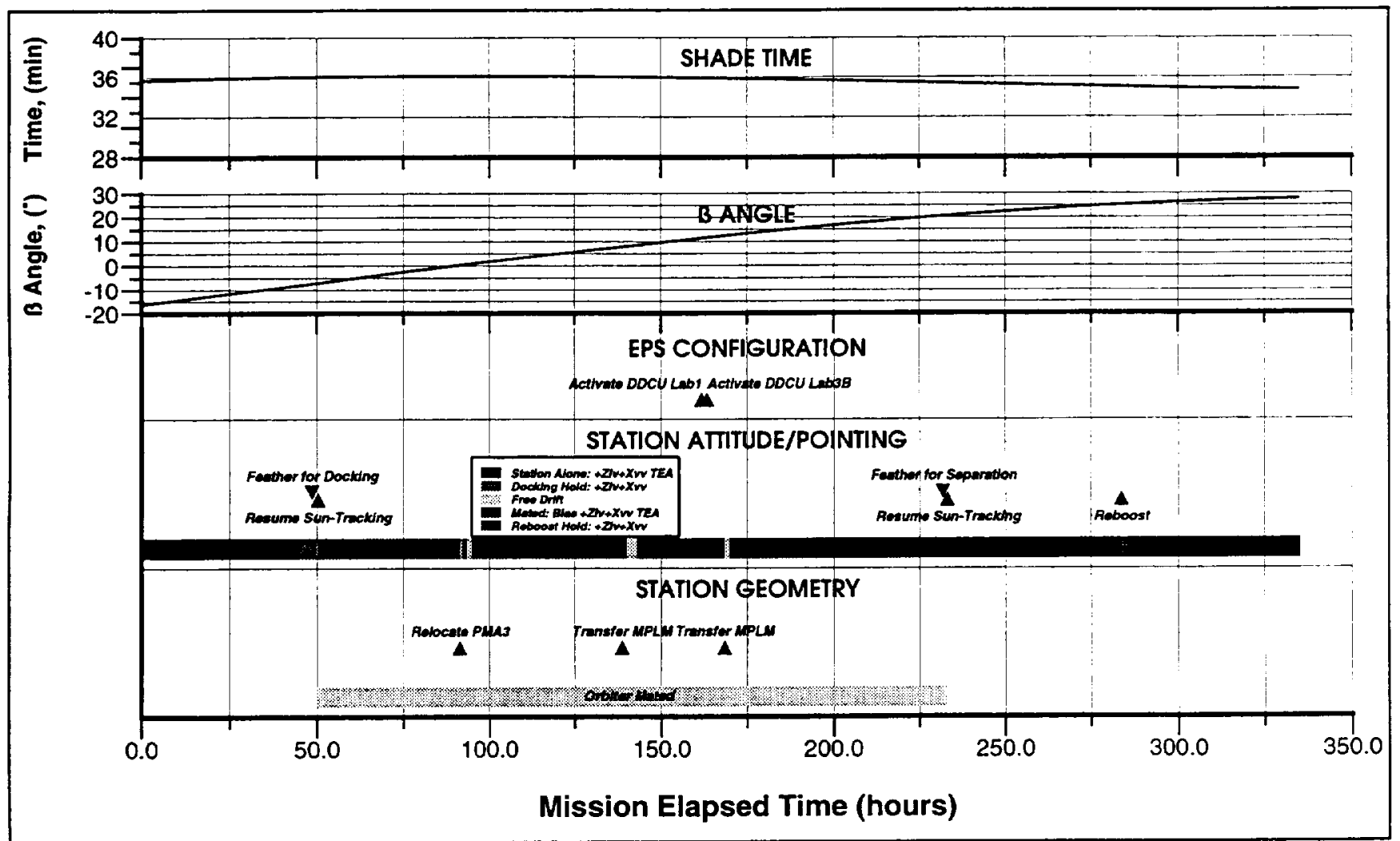

Figure 3: EPS and Station Changes through Example Mission

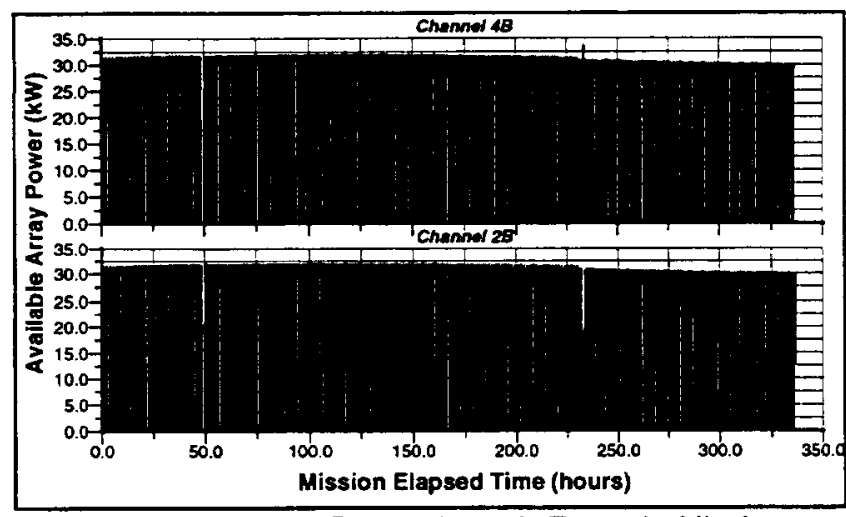

Figure 4: Solar Array Power through Example Mission

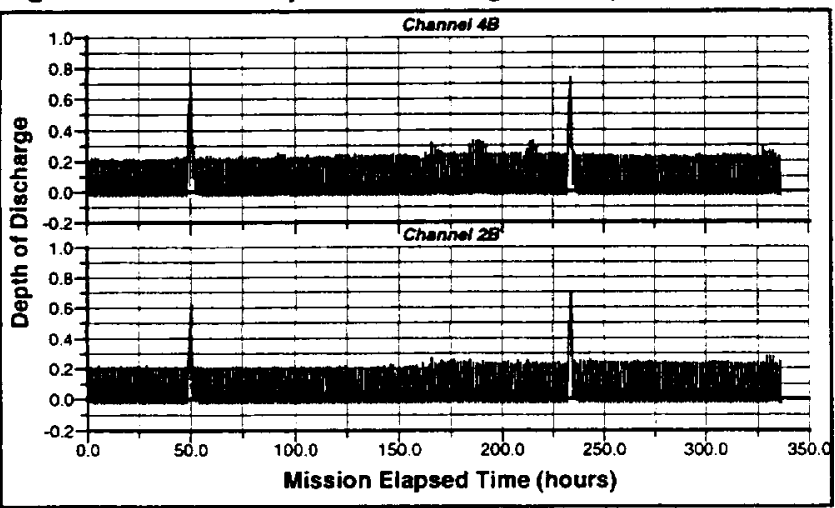

Figure 5: Battery DOD through Example Mission

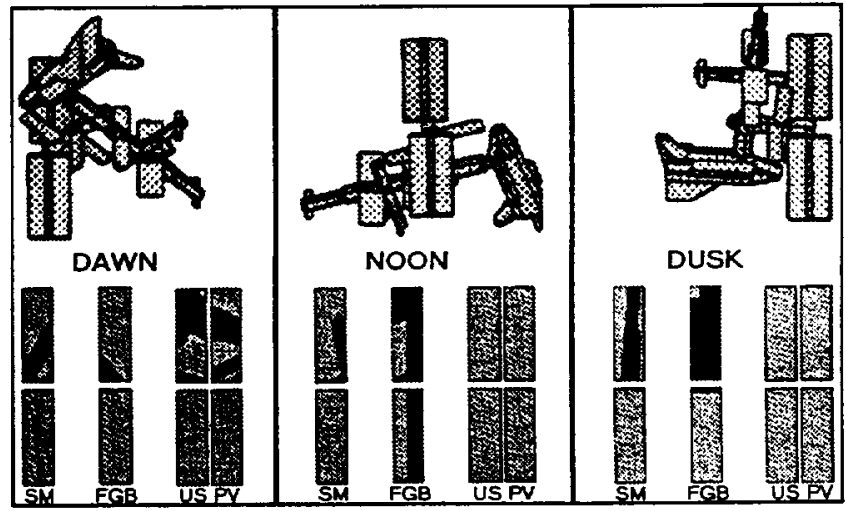

Figure 6: Shadow Pattern from Example Mission

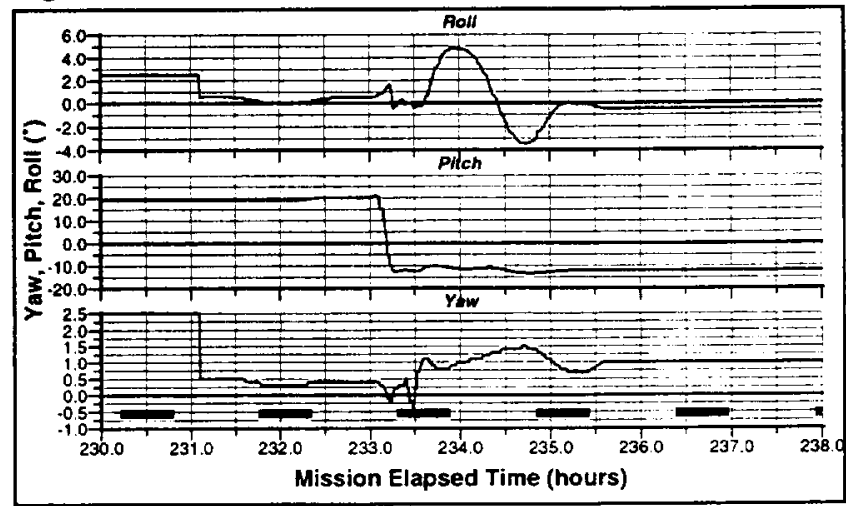

Figure 7: Station Attitude during Shuttle Separation 


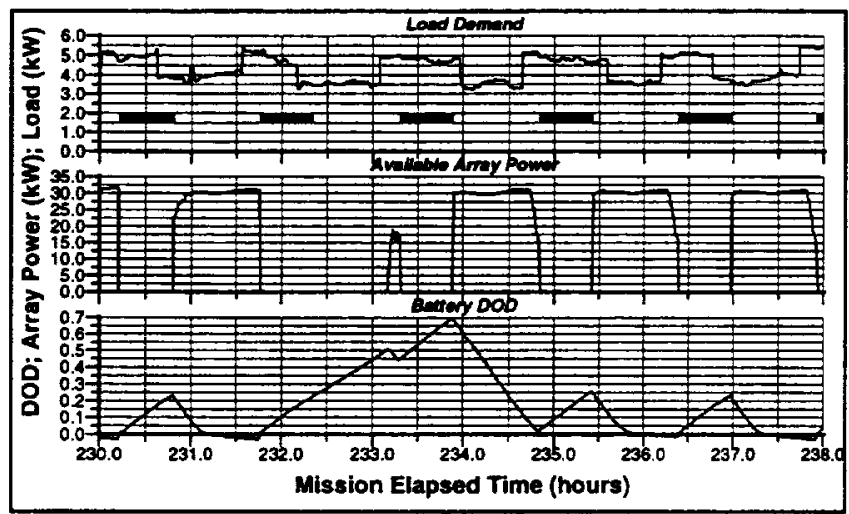

Figure 8: Load Demand, Array Power and DOD during Shuttle Separation

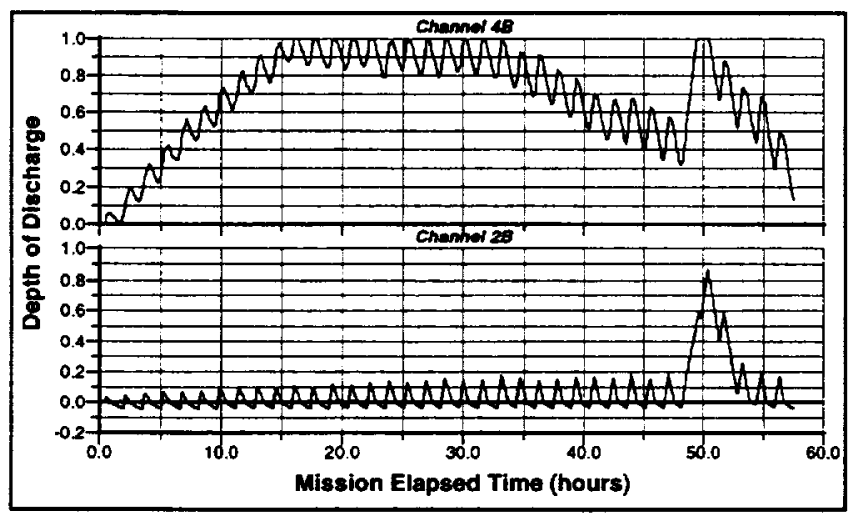

Figure 9: DOD from Hypothetical Overload Scenario

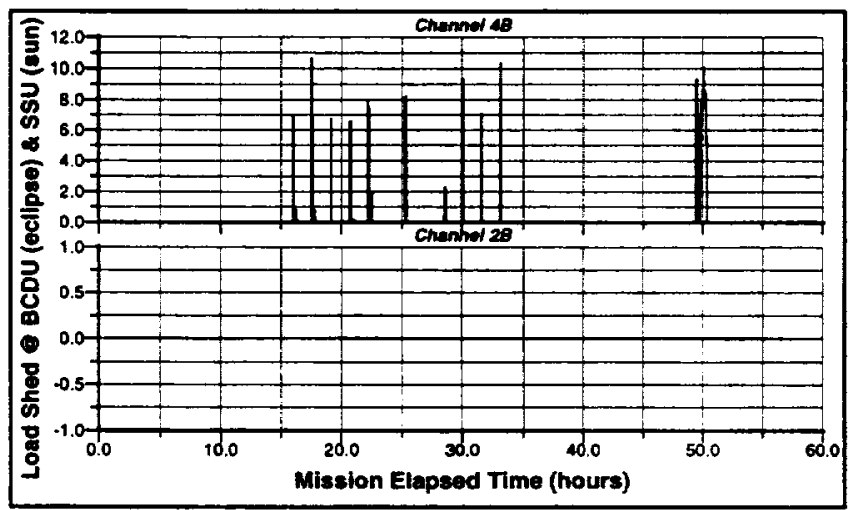

Figure 10:

Load Shed for Hypothetical Overload Scenario

\section{REFERENCES}

Fincannon, J., 1993, "Orbiting Vehicle Shadowing and Power Analysis Computer Programs Integrated," Research and Technology 1993, NASA TM-106376, NASA Lewis Research Center, p.120-121.

Fincannon, J., "Analysis of Shadowing Effects on Spacecraft
Power Systems," NASA TM-106994, Fourth European Space Power Conference, Poitiers, France, September 4-8, 1995.

Fincannon, J., "Analysis of Shadowing Effects on MIR Photovoltaic and Solar Dynamic Power Systems," NASA TM-106940, 30th Intersociety Energy Conversion Engineering Conference, Orlando, Florida, July 31-August 4,1995.

Hojnicki, J. S., 1991, "Computer Code Analyzes Electric Power System Performance," Research and Technology 1991, NASA TM-105320, NASA Lewis Research Center, p. 130-131.

Hojnicki, J. S., McKissock, D. B., and Green, R. D., 1992, "Electric Power System Performance Model Enhanced," Research and Technology 1992, NASA TM-105924, NASA Lewis Research Center, pp. 134.

Hojnicki, J. S., Green, R. D., Kerslake, T. W., McKissock, D. B., and Trudell, J. J., 1993, "Space Station Freedom Electrical Performance Model," NASA TM-106395, Proceedings, 28th Intersociety Energy Conversion Engineering Conference, Atlanta, Georgia.

Kerslake, T. W., Hojnicki, J. S., Green, R. D., and Follo, J. C., 1993, "System Performance Predictions For Space Station Freedom's Electrical Power System," NASA TM-106396, Proceedings, 28th Intersociety Energy Conversion Engineering Conference, Atlanta, Georgia.

Kerslake, T. W. and Fincannon, J., "Analysis of Solar Receiver Flux Distributions for US/Russian Solar Dynamic System Demonstration on the MIR Space Station," NASA TM-106933, 30th Intersociety Energy Conversion Engineering Conference, Orlando, Florida, July 31-August 4, 1995.

Morris, G. M., "International Space Station Flights 4A, 5R Approach, 5A and 6A EPS and Thermal Analysis to Support DAC \#3," MDAC TM-96-0014-01, McDonnell Douglas Aerospace, 1996.

Morris, G. M. and Sheppard, M. A., "Spacecraft Electrical Power System (EPS) Generic Analysis Tools and Techniques," 27th Intersociety Energy Conversion Engineering Conference, San Diego, Califomia, August 3-7, 1992.

\section{ACKNOWLEDGEMENTS}

The authors wish to acknowledge the EPS System Analysis Staff at the International Space Station Product Group 2 Contractor, Rockwell International Corporation, Rocketdyne Division. Their contributions include: 1) establishing and updating hardware component performance parameters used as input to ECAPS, and 2) parallel and complementary development of EPS modeling codes.

The authors also wish to acknowledge all the individuals at the International Space Station Program Office who provide the input data for these analyses. Although there are too many names to list individually, these detailed analyses are not possible without their timely and detailed input data. 



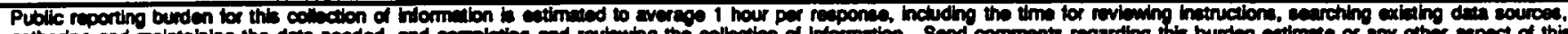

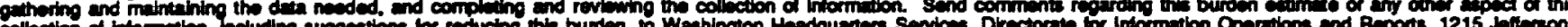

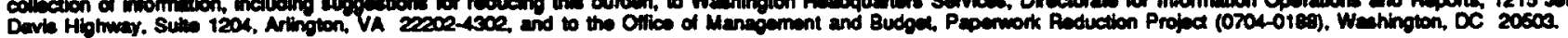
1. AGENCY USE ONL (Laave blank)
2. FiEPOFT DATE
July 1996
3. FEPOFT TYPE AND DATES COVEAED
Technical Memorandum

4. TITL AND SUBTTLE

Load-Following Power Timeline Analyses for the International Space Station

6. AUTHOR(S)

James Fincannon, Ann Delleur, Robert Green, and Jeffrey Hojnicki

5. FUNDING NUMBERS

WU-478-29-10

7. PERFORIING ORGANZATION MAME(S) ND ADDRESS(ES)

National Aeronautics and Space Administration

Lewis Research Center

Cleveland, Ohio 44135-3191

8. PEAFORIMNG ORGAMIZATION PEPORT MUNBER

E-10328

9. SPONSORNGMONTOFING AGENCY MAME(S) AND ADDRESS(ES)

10. SPONSOFINGMONTOFING AGENCY REPORT NUMBER

National Aeronautics and Space Administration

Washington, D.C. 20546-0001

NASA TM-107263

11. SUPPLEMENTARY MOTES

Prepared for the 31st Intersociety Energy Conversion Engineering Conference cosponsored by IEEE, AIChE, ANS, SAE, AIAA, and ASME, Washington, D.C., August 11-16, 1996. Responsible person, James Fincannon, organization code 6920, (216) 433-5405.

12a. DISTFABUTONVAVALABILTY STATENENT 12b. DISTRIBUTION CODE

Unclassified - Unlimited

Subject Categories 20 and 17

This publication is available from the NASA Center for AeroSpace Information, (301) 621-0390.

13. ABSTRACT (Mindmum 200 monds)

Spacecraft are typically complex assemblies of interconnected systems and components that have highly time-varying thermal, communications, and power requirements. It is essential that systems designers be able to assess the capability of the spacecraft to meet these requirements which should represent a realistic projection of demand for these resources once the vehicle is on-orbit. To accomplish the assessment from the power standpoint, a computer code called ECAPS has been developed at NASA Lewis Research Center that performs a load-driven analysis of a spacecraft power system given timevarying distributed loading and other mission data. This program is uniquely capable of synthesizing all of the changing spacecraft conditions into a single, seamless analysis for a complete mission. This paper presents example power load timelines with which numerous data are integrated to provide a realistic assessment of the load-following capabilities of the power system. Results of analyses show how well the power system can meet the time-varying power resource demand.

14. SUBJECT TERMS

Space Stations; Electric power, Power modules; Load-following; Power timeline 15. NUMBER OF PAGES 8

16. PRICE CODE $\mathrm{AO2}$
17. SECURTY CLASSIFICATION OF REPORT Unclassified

18. SECUATY CLASSIFICATION
OF THIS PAGE
Unclassified
19. SECURTY CLASSIFICATION OF ABSTRACT Unclassified





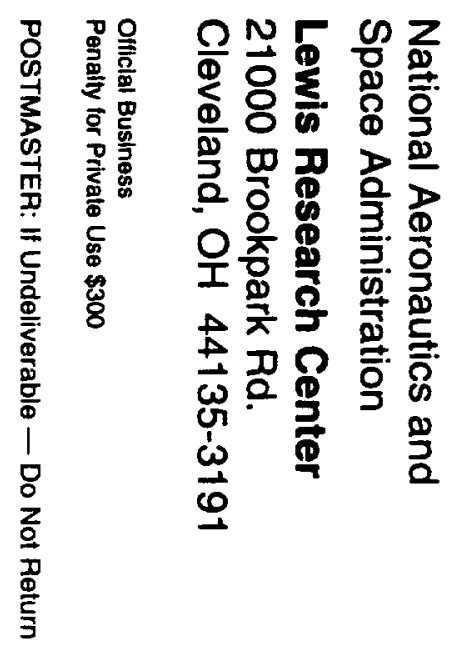

